\title{
Effect of Deep Breathing on Functional Capacity among Healthcare Workers Wearing FFP2/N95 Filtering Facepiece Respirators
}

\author{
SHIMAA T.M. TAHA, M.Sc.*; ZAHRA M.H. SERRY, Ph.D.*; EMAD M.I. TAHA, Ph.D.* and \\ YOUSSEF M.A. SOLIMAN, M.D.** \\ The Department of Physical Therapy for Cardiovascular, Respiratory Disorders \& Geriatrics* and \\ Internal Medicine Department**, Faculty of Medicine, Cairo University
}

\begin{abstract}
Background: The novel 2019 coronavirus disease (COVID-19) pandemic is putting the world at risk due to the spread of virus-infected respiration droplets. Healthcare workers (HCWs) wear N95 respirators to avoid this infection but Wearing it invokes several physiologic implications with prolonged use.
\end{abstract}

Aim of Study: The aim of this study was to measure the effect of deep breathing on functional capacity among healthcare workers wearing FFP2/N95 filtering facepiece respirators.

Subjects and Methods: Sixty HCWs (14 males and 46 females) wearing FFP2/N95 filtering facepiece respirators, their age ranged from (25-35) years old and body mass index (BMI) less than $30 \mathrm{~kg} / \mathrm{m} 2$. participants were recruited from intensive care unit department and inpatient clinics, Cairo University Hospitals, Egypt. Participants were assigned into two groups equal in number; the group (A) ( 22 females $\& 8$ men) performed deep breathing training by incentive spirometer (IS) daily for 6 weeks, while the group (B) (24 females $\& 6$ men) was the control group. Both groups were wearing the respirator for $4-8 \mathrm{~h} /$ day. Data obtained regarding six-minute walk test (6MWT) at the beginning of the study and after 6 weeks for both groups. Parameters were evaluated include heart rate (HR), oxygen saturation $\left(\mathrm{SPO}_{2}\right)$, modified borg dyspnea scale (MBS) and six-minute walking distance (6MWD) without wearing N95 mask, while wearing N95 mask from 2 hours Pre training and while wearing N95 mask from 2 hours Post training after 6 weeks also breath holding time (BHT) was measured at the beginning and the end of the study.

Results: After 6 weeks of training, there was no significant difference between groups in $\mathrm{HR}, \mathrm{O}_{2}$ saturation and 6MWD at Pre training without mask and at Pre training with mask $(p>0.05)$. However, there was a significant decrease in resting HR, HR after 6MWT, resting MBS and MBS after 6MWT at Post training with mask of study group compared with that of control group $(p<0.001)$. There was a significant increase in resting $\mathrm{O}_{2}$ saturation, $\mathrm{O}_{2}$ saturation after 6MWT and 6MWD at Post training with mask of study group compared with that of control group $(p<0.01)$. There was a significant increase in the BHT of study group compared with that of control group Post training $(p<0.001)$.

Correspondence to: Dr. Shimaa T.M. Taha, E-Mail: shimaa.taha395@gmail.com
Conclusion: The results demonstrated that deep breathing training improve functional capacity among healthcare workers wearing FFP2/N95 filtering facepiece respirators.

Key Words: Deep breathing - Functional capacity - FFP2/N95 filtering facepiece respirators.

\section{Introduction}

ON March 11, 2020, the World Health Organization (WHO) declared COVID-19 to be a pandemic [1] As COVID-19 pandemic spreads across the world, millions of people are remaining at home to slow the spread of the disease and help to flatten the curve associated with the exponential increase in the number of cases. HCWs on the other hand, will not be staying at home [2]. During the ongoing COVID-19 outbreak, it is recommended that HCWs in close contact with infected patients wear N95 filtering facepiece respirators (FFR) rather than surgical masks [3], due to medical masks, also known as surgical masks, are less effective than N95 FFR at minimizing aerosol exposure [4] .

The use of a N95 FFR induces a rise in inhaled carbon dioxide ( $\mathrm{CO} 2)$, a decrease in inspired oxygen $\left(\mathrm{O}_{2}\right)$, and an increase in work of breathing. Transient acidosis and compensatory increases in minute ventilation, work of breathing, and cardiac output result from the inhaled carbon dioxide of 2 to 3 percent (normal, 0.04 percent) [5] . In general, wearing a mask increases the resistance to breathe, resulting in an increase in $\mathrm{CO}_{2}$ in the mask's dead space. As a result, the wearer would have to exert more effort to breathe, causing discomfort and fatigue [6]. In healthy young subjects, surgical masks decrease cardiopulmonary exercise capacity and ventilation, and wearing masks can affect aerobic exercise capacity [7]. Reduced forced vital ability (FVC), forced expiratory volume in one second (FEV1) and peak expiratory flow (PEF) 
with the surgical mask and even greater impairments with the FFP2/N95 FFR. Wearing the FFP2/ N95 FFR resulted in a reduction of maximum oxygen uptake (VO2max) by 13 percent and of ventilation by 23 percent. These results correspond to a rise in airway resistance [8]

The cardiorespiratory functions improve with regular practice of the deep breathing technique. Previous studies have shown that it is well known to reduce the effects of stress, which, in turn, increases an individual's physical and mental health [9] . Incentive spirometer (IS) is intended to help you reach and maintain maximum inspiration. It is easy to use and gives visual feedback to the user. Its use leads to a longer period of successful inspiration, a more regulated flow, and an increased desire to practice [10], also IS helped to improve cardiopulmonary function and functional capacity [11].

Field walking tests are frequently used to assess functional capacity [12]. For a long time, timed walking tests have been used to assess functional exercise performance. 6MWT is among modalities available for objective assessment of functional exercise capacity [13]. The 6MWT is a simple test that objectively assesses a patient's functional capacity [14] . A substantial body of literature has been published on the validity and repeatability of the 6MWT in healthy children and adolescents [15] . It has been shown to correlate well with pulmonary function test (PFT) variables such as forced expiratory volume in one second (FEV1), forced vital ability (FVC), and carbon monoxide diffusion capacity (DLCO) [16]

\section{Subjects and Methods}

This study had approval of the Ethics Committee of Faculty of Physical Therapy, Cairo University, NO: P.T.REC/012/002978 Egypt. Participants fully understood the purpose and methods of the study, which complied with the ethical standards. Written informed consent was obtained from each participant.

Included and excluded of participants were according to the following criteria.

Inclusion criteria: Sixty participants, Age ranged from 25-35 years, both genders could participate, working at intensive care units and inpatient clinics. Subjects were assigned into two groups, thirty in each group; the group (A) $(22$ females \& 8 men) the study group who performed deep breathing training using incentive spirometer, while the group (B) (24 females \& 6 men) was the control group wearing FFP2/N95 FFR 4-8h/day as the study group, BMI less than $30 \mathrm{~kg} / \mathrm{m}^{2}$, Wearing FFP2/N95 FFR 4-8h/day, Active but not involved in any competitive sport. They had been recruited from Intensive Care Unit Department and Inpatient Clinics, Cairo University Hospitals, Egypt. They were received their training program from November 2020 to February 2021.

Exclusion criteria: Smokers' participants, Chronic respiratory diseases history including chronic obstructive pulmonary disease (COPD) and asthma, showing respiratory tract infection symptoms within last two weeks, History of chronic disease that could influence their exercise capacity, Walking Disability due to neurological or musculoskeletal condition, History of cardiac diseases, Pregnant women, Obese (BMI greater than $30 \mathrm{~kg} /$ $\mathrm{m}$ ), Tachycardia, Hypertension, Sinusitis.

\section{Randomization:}

The participants were randomly assigned to group (A) $(n=30)$ and group (B) $(n=30)$ by an independent person who selected blindly from sealed envelopes containing numbers created by a random number generator. The randomization was restricted to permuted blocks to ensure that equal numbers were allocated to each group $\mathrm{A}$ and group $\mathrm{B}$. The sequences assigned to the participants were placed in enveloped containing the allocation to each group. The aim and procedures of the study were informed to eligible participants.

\section{Measures and Equipment:}

\section{A- Evaluating Equipment:}

Six-minute walking distance equipment: Stopwatch, Mechanical lap counter, two small cones, A portable chair that can be moved along the walking path, Worksheets on a clipboard, 30-meter wind-up tape measure.

Body weight and height scale: Weight and height scale to calculate (BMI) for subjects' selection (UGM 200 health scale), Mercury sphygmomanometer \& pulse oximeter: KBM blood Pressure Measuring Device Model Number: Sm300 and Yuwell stethoscope, Portable pulse oximeter (Choice Med Oxy Watch): Monitoring of arterial oxygen saturation $(\mathrm{SpO} 2)$ and heart rate $(\mathrm{HR})$.

\section{B- Training Equipment:}

Incentive spirometer [MEDITREAT (M-6026)] - 3 balls incentive spirometer.

Preliminary assessment: Before and after each 6MWT, HR, BP, SPO2, and Borg value were recorded [13]. BHT and BMI was also measured. 
Functional capacity test (6MWT): In this study, three measurements result of 6-MWT was taken: 6-MWT Pre training without mask (both groups), 6-MWT Pre training with mask from $2 \mathrm{~h}$ (both groups) and 6-MWT Post training with mask from $2 \mathrm{~h}$ after 6 weeks of breathing exercise training using incentive spirometer for the (study group) and without training for the (control group). Incentive spirometry training program for group A: Subjects were instructed to take five sets of five sustained maximal inspirations and expirations twice a day, for a total of 50 maximal inspirations and expirations everyday using an incentive spirometer. Daily for 6 weeks [17].

Statistical analysis: After collecting data, Unpaired $t$-test was conducted for comparison of the age and BMI between groups. Chi squared test was conducted for comparison of sex distribution between groups. The normality of data was assessed using Shapiro-Wilk test and Levene's test was used to assess the equality of variances. Mixed MANOVA was conducted for within and between group effects on mean values of $\mathrm{HR}, \mathrm{O}_{2}$ saturation and 6MWD. Multiple post-hoc tests were conducted using the Bonferroni correction. Mann-Whitney $\mathrm{U}$ test was conducted for comparison of median values of MBS between groups and Friedman test and Wilcoxon signed ranks test were conducted for within group comparison of median values of MBS in each group. Unpaired $t$-test was conducted for comparison of BHT between groups. Paired $t$ test was conducted for comparison between pre and Post training BHT in each group. Statistical measures were performed through the statistical package for social studies (SPSS) version 22 for windows. The level of significance for all statistical tests was set at $p<0.05$.

\section{Results}

\section{Subject characteristics:}

Sixty healthcare workers wearing FFP2/N95 filtering facepiece respirators participated in this stud. Subjects' characteristics presented in Table (1). There was no significant difference in the age, BMI, and sex distribution between groups $(p>0.05)$. (Table 1).

\section{Between group comparison:}

There was no significant difference between groups in $\mathrm{HR}, \mathrm{O}_{2}$ saturation and 6MWD at Pre training without mask and at Pre training with mask $(p>0.05)$. However, there was a significant decrease in resting HR and HR after 6MWT at Post training with mask of study group compared with that of control group $(p<0.001)$. There was a significant increase in resting $\mathrm{O}_{2}$ saturation, $\mathrm{O}_{2}$ saturation after 6MWT and 6MWD at Post training with mask of study group compared with that of control group $(p<0.01)$. (Table 2$)$.

There was a significant decrease in resting MBS and MBS after 6MWT at Post training with mask of study group compared with that of control group $(p<0.001)$. (Table 3).

There was a significant increase in the BHT of study group compared with that of control group Post training $(p<0.001)$. (Table 4$)$.

\section{Within group comparison:}

\section{Study group:}

There was a significant increase in resting HR and HR after 6MWT Pre training with mask compared with that Pre training without mask and Post training with mask $(p<0.001)$. There was no significant difference in resting HR between Pre training without mask and Post training with mask $(p>0.05)$ while there was a significant decrease in HR after 6MWT Post training with mask compared with that Pre training without mask $(p<0.05)$.

There was a significant decrease in resting $\mathrm{O}_{2}$ saturation, $\mathrm{O}_{2}$ saturation after 6MWT and 6MWD Pre training with mask compared with that Pre training without mask $(p<0.01)$. There was a significant increase in resting $\mathrm{O}_{2}$ saturation, $\mathrm{O}_{2}$ saturation after 6MWT and 6MWD Post training with mask compared with Pre training without mask $(p<0.05)$. There was a significant increase in resting $\mathrm{O}_{2}$ saturation, $\mathrm{O}_{2}$ saturation and 6MWD after 6MWT Post training with mask compared with that Pre training with mask $(p<0.001)$.

There was a significant increase in resting MBS and MBS after 6MWT Pre training with mask compared with that Pre training without mask and Post training with mask $(p<0.001)$. There was a significant increase in resting MBS Post training with mask compared with Pre training without mask $(p<0.01)$. There was no significant difference in MBS after 6MWT between Pre training without mask and Post training with mask ( $p>0.05)$. There was a significant increase in the BHT of the study group Post training compared with that Pre training $(p<0.001)$. (Tables 2,3,4).

\section{Control group:}

There was a significant increase in resting HR and HR after 6MWT Pre training with mask compared with that Pre training without mask ( $p<$ 0.001 ). There was a significant increase in resting HR and HR after 6MWT at Post training with mask 
compared with Pre training without mask ( $p<$ 0.001 ). There was no significant difference in resting HR and HR after 6MWT between Pre training with mask and Post training with mask ( $p>0.05)$.

There was a significant decrease in resting $\mathrm{O}_{2}$ saturation and $\mathrm{O}_{2}$ saturation after 6MWT Pre training with mask compared with that Pre training without mask $(p<0.05)$. There was no significant difference in resting $\mathrm{O}_{2}$ saturation and $\mathrm{O}_{2}$ saturation after 6MWT between Pre training without mask and Post training with mask $(p=0.19)$. There was no significant difference in resting $\mathrm{O}_{2}$ saturation and $\mathrm{O}_{2}$ saturation after $6 \mathrm{MW}$ between Pre training with mask and Post training with mask $(p>0.05)$.

There was a significant increase in resting MBS and MBS after 6MWT Pre training with mask compared with that Pre training without mask $(p=0.0001)$. There was a significant increase in resting MBS and MBS after 6MWT Post training with mask compared with Pre training without mask $(p<0.001)$. There was no significant difference in resting MBS and MBS after 6MWT between Pre training with mask and Post training with mask $(p>0.05)$. There was no significant difference in the BHT between pre and Post training $(p>0.05)$. (Tables 2,3,4).

Table (1): Basic characteristics of participants.

\begin{tabular}{lccc}
\hline & Group A & Group B & $p$-value \\
\hline Age, mean $\pm(\mathrm{SD})$, years & $27.8 \pm 2.12$ & $28.03 \pm 2.89$ & 0.76 \\
BMI, mean $\pm(\mathrm{SD}), \mathrm{kg} / \mathrm{m}^{2}$ & $24.77 \pm 2.95$ & $24.74 \pm 3.57$ & 0.96 \\
Sex, $n(\%):$ & & & \\
$\quad$ Females & $22(73 \%)$ & $24(80 \%)$ & 0.54 \\
$\quad$ Males & $8(27 \%)$ & $6(20 \%)$ & \\
\hline
\end{tabular}

SD: Standard deviation; $p$-value, level of significance.

Table (2): Mean resting HR, resting $\mathrm{O}_{2}$ saturation, 6MWD, HR after 6MWT and $\mathrm{O}_{2}$ saturation after 6MWT Pre training without mask, Pre training with mask and Post training with mask of the study and control groups.

\begin{tabular}{|c|c|c|c|c|c|c|}
\hline & $\begin{array}{l}\text { Pre training } \\
\text { without mask }\end{array}$ & $\begin{array}{l}\text { Pre training } \\
\text { with mask }\end{array}$ & $\begin{array}{l}\text { Post training } \\
\text { with mask }\end{array}$ & \multicolumn{3}{|c|}{$p$-value } \\
\hline & Mean \pm SD & Mean \pm SD & Mean \pm SD & $\begin{array}{c}\text { Pre training } \\
\text { without } \\
\text { mask vs } \\
\text { Pre training } \\
\text { with mask }\end{array}$ & $\begin{array}{l}\text { Pre training } \\
\text { without } \\
\text { mask vs } \\
\text { Post training } \\
\text { with mask }\end{array}$ & $\begin{array}{l}\text { Pre training } \\
\text { with mask vs } \\
\text { Post training } \\
\text { with mask }\end{array}$ \\
\hline \multicolumn{7}{|c|}{ Resting HR (beats/min): } \\
\hline Study group & $81.06 \pm 6.73$ & $86.07 \pm 5.86$ & $79.03 \pm 6$ & 0.001 & 0.44 & 0.001 \\
\hline Control group & $\begin{array}{l}78.87 \pm 7.13 \\
p=0.22\end{array}$ & $\begin{array}{l}84.23 \pm 6.85 \\
p=0.27\end{array}$ & $\begin{array}{l}85.7 \pm 9.14 \\
p=0.001\end{array}$ & 0.001 & 0.001 & 0.73 \\
\hline \multicolumn{7}{|c|}{ HR after $6 M W T$ (beats/min): } \\
\hline Study group & $100.6 \pm 8.31$ & $109.46 \pm 8.2$ & $96.36 \pm 7.95$ & 0.001 & 0.02 & 0.001 \\
\hline Control group & $\begin{array}{l}97.33 \pm 7.83 \\
p=0.12\end{array}$ & $\begin{array}{l}108.16 \pm 7.57 \\
p=0.52\end{array}$ & $\begin{array}{l}110.26 \pm 9.31 \\
p=0.001\end{array}$ & 0.001 & 0.001 & 0.5 \\
\hline \multicolumn{7}{|c|}{ Resting O2 saturation (\%): } \\
\hline Study group & $98.23 \pm 0.89$ & $97.96 \pm 0.88$ & $98.6 \pm 0.62$ & 0.01 & 0.03 & 0.001 \\
\hline Control group & $\begin{array}{l}98.3 \pm 0.95 \\
p=0.78\end{array}$ & $\begin{array}{l}98.06 \pm 0.94 \\
p=0.67\end{array}$ & $\begin{array}{l}98.13 \pm 0.82 \\
p=0.01\end{array}$ & 0.02 & 0.73 & 1 \\
\hline \multicolumn{7}{|c|}{ O2 saturation after $6 M W T(\%)$ : } \\
\hline Study group & $97.9 \pm 0.99$ & $97.43 \pm 0.89$ & $98.46 \pm 0.68$ & 0.01 & 0.03 & 0.001 \\
\hline Control group & $\begin{array}{l}98.16 \pm 1.11 \\
p=0.33\end{array}$ & $\begin{array}{l}97.63 \pm 0.96 \\
p=0.4\end{array}$ & $\begin{array}{l}97.76 \pm 0.77 \\
p=0.001\end{array}$ & 0.006 & 0.19 & 1 \\
\hline \multicolumn{7}{|l|}{$6 M W D(m):$} \\
\hline Study group & $451.67 \pm 48.97$ & $410.63 \pm 47.43$ & $495.73 \pm 52.1$ & 0.001 & 0.001 & 0.001 \\
\hline Control group & $\begin{array}{l}457.43 \pm 41.76 \\
p=0.62\end{array}$ & $\begin{array}{l}410.26 \pm 45.04 \\
p=0.97\end{array}$ & $\begin{array}{l}390.46 \pm 51.76 \\
p=0.001\end{array}$ & 0.001 & 0.001 & 0.004 \\
\hline
\end{tabular}

SD: Standard deviation; $p$-value, level of significance. 
Table (3): Median values od resting MBS and MBS after 6MWT Pre training without mask, Pre training with mask and Post training with mask of the study and control groups.

\begin{tabular}{|c|c|c|c|c|c|c|}
\hline & \multirow{2}{*}{$\begin{array}{c}\begin{array}{c}\text { Pre training } \\
\text { without mask }\end{array} \\
\\
\text { Mean } \pm \text { SD }\end{array}$} & \multirow{2}{*}{$\begin{array}{c}\begin{array}{c}\text { Pre training } \\
\text { with mask }\end{array} \\
\\
\text { Mean } \pm \text { SD }\end{array}$} & \multirow{2}{*}{$\begin{array}{c}\begin{array}{c}\text { Post training } \\
\text { with mask }\end{array} \\
\text { Mean } \pm \text { SD }\end{array}$} & \multicolumn{3}{|c|}{$p$-value } \\
\hline & & & & $\begin{array}{c}\text { Pre training } \\
\text { without } \\
\text { mask vs } \\
\text { Pre training } \\
\text { with mask }\end{array}$ & $\begin{array}{l}\text { Pre training } \\
\text { without } \\
\text { mask vs } \\
\text { Post training } \\
\text { with mask }\end{array}$ & $\begin{array}{c}\text { Pre training } \\
\text { with mask vs } \\
\text { Post training } \\
\text { with mask }\end{array}$ \\
\hline \multicolumn{7}{|l|}{ Resting MBS: } \\
\hline Study group & $0(0.5-0)$ & $1(2-0.5)$ & $0.5(1-0)$ & 0.001 & 0.003 & 0.001 \\
\hline Control group & $\begin{array}{l}0(0.5-0) \\
p=0.73\end{array}$ & $\begin{array}{l}1(2-0.87) \\
p=0.83\end{array}$ & $\begin{array}{c}1(2-1) \\
p=0.001\end{array}$ & 0.001 & 0.001 & 0.41 \\
\hline \multicolumn{7}{|l|}{$M B S$ after $6 M W T:$} \\
\hline Study group & $1(1-0.5)$ & $3(3-2)$ & $1(2-0.5)$ & 0.001 & 0.34 & 0.001 \\
\hline Control group & $\begin{array}{l}0.75(1-0.5) \\
p=0.42\end{array}$ & $\begin{array}{l}3(4-2) \\
p=0.47\end{array}$ & $\begin{array}{l}3(4-2) \\
p=0.001\end{array}$ & 0.0001 & 0.0001 & 0.48 \\
\hline
\end{tabular}

SD: Standard deviation; $p$-value, level of significance.

Table (4): Mean BHT pre and Post training of the study and control groups.

\begin{tabular}{llll}
\hline & $\begin{array}{c}\text { Pre training } \\
\text { Mean } \pm \mathrm{SD}\end{array}$ & $\begin{array}{c}\text { Post training } \\
\text { Mean } \pm \mathrm{SD}\end{array}$ & $\begin{array}{c}p \text { - } \\
\text { value }\end{array}$ \\
\hline BHT (sec): & & & \\
Study group & $44.86 \pm 9.35$ & $54.23 \pm 8.14$ & 0.001 \\
Control group & $\begin{array}{l}46.3 \pm 9.62 \\
\end{array}$ & $\begin{array}{l}45.93 \pm 9.97 \\
\end{array}$ & 0.62 \\
& $p=0.65$ & $p=0.001$ & \\
\hline
\end{tabular}

SD: Standard deviation; $p$-value, level of significance.

\section{Discussion}

From the results shown above, the current study reflected an improvement of functional capacity among healthcare workers wearing FFP2/N95 filtering facepiece respirators after they performed deep breathing training daily for 6 weeks.

The results of this study supported by Nariyani and Vyas [18], who reported that after deep breathing exercise for 5 minutes ( 6 breaths/min) in healthy young individuals, the respiratory rate and heart rate both decreased. Oxygen saturation and breath holding time both improved at the same time.

Results also came coincident with Sunitha and Ravi [19] who stated that, Possible explanations for the substantial increase in breath holding time (BHT) in young healthy study were attributed to the fact that in deep breathing, the phase of inhalation is continued with strong voluntary control, so that the lungs are significantly expanded, and the walls of the alveoli are stretched to the greatest extent possible. As a result, the chest continues to expand under cortical control. Stretch receptors are thus trained to withstand increasing amounts of stretching. This allows them to hold their breath for a longer period. The respiratory center becomes acclimatized to withstand higher $\mathrm{CO} 2$ concentrations in the alveoli and blood as the duration of breath holding during deep breathing is gradually increased by practice.

The results of this study are supported by Russo et al., [20] who provided a thorough overview of normal respiratory physiology as well as the documented physiological effects of slow breathing techniques in healthy humans and discovered that Slow breathing at 6 breaths per minute was discovered to be optimal for improving alveolar ventilation and reducing dead space in both groups in terms of increased oxygen saturation and easiness and sustainability of respiratory effort.

Results also came in line with Pal et al., [21], who revealed that regular practice of slow breathing exercise improves autonomic functions. they discovered a significant decrease in basal heart rate in the slow breathing group. The heart rate in normal resting subjects is primarily determined by background vagal activity. As a result, the parasympathetic nervous system controls the basal heart rate. This suggests that practicing slow breathing exercises improves vagal activity.

The results of this study also supported by Yamaguti et al., [22] who stated that an incentive spirometer is a portable device whose primary function is to encourage deep, slow inhalation up to maximal inspiratory capacity by assessing users with a visual stimulus indicating that the desired flow or volume has been achieved and Abid et al., 
[23] found that deep breathing have a direct influence on the respiratory system because they make ventilation easier and allow an individual to inhale the maximum amount of oxygen after a normal expiration. Breathing exercises cause the diaphragm to fully expand and more air to be inhaled in the lungs, resulting in an increase in stamina and flexibility of the respiratory muscles. deep breathing exercises can improve the effectiveness of the intercostals muscle between the ribs cage, which helps to improve breathing, oxygen saturation, lung function, and, ultimately, quality of life. These exercises are simple to learn and can be done anywhere, at any time.

The results of this study came in agreement with results of Amola et al., [24] and Weiner et al., [25], who demonstrated that inspiratory muscle training was effective and beneficial in relieving dyspnea, fatigue, improving pulmonary functions, and increasing submaximal exercise performance.

Moreover, the result of our study came in agreement with Aweto et al., [26] study, which found that IS improved cardiopulmonary function and functional capacity significantly. The IS group had a statistically significant increase in functional capacity (6MWD) after eight weeks of IS, whereas the control group had no statistically significant increase.

The results of this study came in accordance with Illi et al., [27], who conducted a systematic review and meta-analysis to determine the factors that affect the change in endurance performance after respiratory muscle training (RMT) in healthy subjects, found that regardless of the type of RMT or sport, RMT improves endurance exercise performance in healthy individuals.

Although the result of this study disagreed with a study conducted with Sperlich et al., [28], who found no benefits to 6-week high-intensity respiratory muscle training (RMT) in healthy nonsmokers in terms of maximum or submaximal physical performance, cardiorespiratory data, pulmonary parameters, or perception of respiratory effort. Previous research has partially confirmed the findings. Incongruency with other existing literature is also most likely due to methodological diversity in the pre-post-test design, a lack of control groups, as well as dissimilar training protocols.

Conclusion: Based on the scope and findings of this study, it could be concluded that deep breathing training has significant improvement on functional capacity among healthcare workers wearing FFP2/N95 filtering facepiece respirators.

\section{Authors' Contribution:}

All authors contributed equally to the whole research processes as conceptualization, data curation, investigation, methodology, writing-review $\&$ editing, read and approved the final version of the manuscript, and agree with the order of presentation of the authors.

\section{Funding/Support:}

The authors received no financial support for the research and publication of this article.

\section{Declaration of interest:}

The authors declare that there is no conflict of interest that could be perceived as prejudicing the impartiality of the research reported.

\section{References}

1- BARTOSZKO J.J., FAROOQI M.A.M., ALHAZZANI W. and LOEB M.: Medical masks vs N95 respirators for preventing COVID-19 in healthcare workers: A systematic review and meta-analysis of randomized trials. Influenza and other respiratory viruses, 14 (4): 365-373, 2020.

2- UMER F.A.H.A.D., HAJI Z. and ZAFAR K.A.M.I.L.: Role of respirators in controlling the spread of novel coronavirus (COVID-19) amongst dental healthcare providers: A review. International endodontic journal, 53 (8): 1062-1067, 2020.

3- ZHANG M., EMERY A.R., TANNYHILL R.J., ZHENG H. and WANG J.: Masks or N95 Respirators During COVID-19 Pandemic-Which One Should I Wear?. Journal of Oral and Maxillofacial Surgery, 78 (12): 2114-2127, 2020.

4- NOTI J.D., LINDSLEY W.G., BLACHERE F.M., CAO G., KASHON M.L., THEWLIS R.E. and BEEZHOLD, D.H.: Detection of infectious influenza virus in cough aerosols generated in a simulated patient examination room. Clinical Infectious Diseases, 54 (11): 1569-1577, 2012.

5- SINKULE E.J., POWELL J.B. and GOSS F.L.: Evaluation of N95 respirator use with a surgical mask cover: Effects on breathing resistance and inhaled carbon dioxide. Annals of occupational hygiene, 57 (3): 384-398, 2013.

6- GOH D.Y.T., MUN, M.W., LEE W.L.J., TEOH O.H. and RAJGOR D.D.: A randomised clinical trial to evaluate the safety, fit, comfort of a novel N95 mask in children. Scientific reports, 9 (1): 1-10, 2019.

7- LI M., OU H., LI Q., LIANG J., LIAO W., LANG S. and ZHENG Y.: Effects of Surgical Masks on Cardiopulmonary Function in Healthy Subjects. JoVE (Journal of Visualized Experiments), 168: e62121, 2021.

8- FIKENZER S., UHE T., LAVALL D., RUDOLPH U., FALZ R., BUSSE M. and LAUFS U.: Effects of surgical and FFP2/N95 face masks on cardiopulmonary exercise capacity. Clinical Research in Cardiology, 109 (12): 15221530, 2020.

9- DINESH T., RAJAJEYAKUMAR M. and SAKILA S.: Effect of 12 weeks of slow breathing exercise practice on anthropometric parameters in healthy volunteers. 
National Journal of Physiology, Pharmacy and Pharmacology, 8 (12): 1650-1653, 2018.

10- WESTWOOD K., GRIFFIN M., ROBERTS K., WILLIAMS M., YOONG K. and DIGGER T.: Incentive spirometry decreases respiratory complications following major abdominal surgery. The Surgeon, 5 (6): 339-342, 2007.

11- AWETO H.A., OBIKEH E. O. and TELLA B.A.: Effects of incentive spirometry on cardiopulmonary parameters, functional capacity and glycemic control in patients with Type 2 diabetes. Hong Kong Physiotherapy Journal, 40 (02): 121-132, 2020.

12- HOLLAND A.E., SPRUIT M.A., TROOSTERS T., PUHAN M.A., PEPIN V., SAEY D. and SINGH S.J.: An official European Respiratory Society/American Thoracic Society technical standard: Field walking tests in chronic respiratory disease. European Respiratory Journal, 44 (6): 1428-1446, 2014.

13- OLIVEIRA M.J., MARÇÔA R., MOUTINHO J., OLIVEIRA P., LADEIRA I., LIMA R. and GUIMARÃES M.: Reference equations for the 6-minute walk distance in healthy Portuguese subjects 18-70 years old. Pulmonology, 25 (2): 83-89, 2019.

14- DU H., WONGGOM P., TONGPETH J. and CLARK R.A.: Six-minute walk test for assessing physical functional capacity in chronic heart failure. Current heart failure reports, 14 (3): 158-166, 2017.

15- PAPATHANASIOU J.V., ILIEVA E. and MARINOV B.: Six-minute walk test: an effective and necessary tool in modern cardiac rehabilitation. Hellenic J. Cardiol., 54 (2): 126-30, 2013.

16- GUPTA R., RUPPEL G.L. and ESPIRITU J.R.D.: Exercise-induced oxygen desaturation during the 6-minute walk test. Medical Sciences, 8 (1): 8, 2020.

17- KOTANI T., AKAZAWA T., SAKUMA T., NAGAYA S., SONODA M., TANAKA Y. and MINAMI S.: Effects of incentive spirometry on respiratory motion in healthy subjects using cine breathing magnetic resonance imaging Annals of rehabilitation medicine, 39 (3): 360-365, 2015.

18- NARIYANI P. and VYAS H.: Immediate effect of deep breathing exercise on healthy. Int. J. Physiother Res., 5 (5): 2420-2423, 2017.

19- SUNITHA G. and RAVI B.N.: Effect of deep breathing on respiratory parameters in healthy young individuals. Journal of Evolution of Medical and Dental Sciences, 2 (19): 3305-3313, 2013

20- RUSSO M.A., SANTARELLI D.M. and O'ROURKE D. The physiological effects of slow breathing in the healthy human. Breathe, 13 (4): 298-309, 2017.

21- PAL G.K., VELKUMARY S. and MADANMOHAN Effect of short-term practice of breathing exercises on autonomic functions in normal human volunteers. The Indian journal of medical research, 120 (2): 115-121, 2004.

22- YAMAGUTI W.P.D.S., SAKAMOTO E.T., PANAZZOLO D., PEIXOTO C.D.C., CERRI G.G. and ALBUQUERQUE A.L.P.: Diaphragmatic mobility in healthy subjects during incentive spirometry with a flow-oriented device and with a volume-oriented device. Jornal Brasileiro de Pneumologia, 36 (6): 738-745, 2010.

23- ABID N., RAO A.R., BABAR M.N., ANSARI M. and AWAN W.A.: Effect of deep breathing exercises in healthy smokers: A pilot study. JPMA. The Journal of the Pakistan Medical Association, 70 (7): 1209-1213, 2020.

24- AMOLA M., PAWARA S. and KALRA S.: Effect of Inspiratory Muscle Training and Diaphragmatic Breathing Exercises on Dyspnea, Pulmonary Functions, Fatigue and Functional Capacity in Pregnancy during Third Trimester. Journal of Clinical \& Diagnostic Research, 13 (8), 2019.

25- WEINER P., MAGADLE R., BECKERMAN M., WEINER M. and BERAR-YANAY N.: Comparison of specific expiratory, inspiratory, and combined muscle training programs in COPD. Chest, 124 (4): 1357-1364, 2003.

26- AWETO H.A., OBIKEH E.O. and TELLA B.A.: Effects of incentive spirometry on cardiopulmonary parameters, functional capacity and glycemic control in patients with Type 2 diabetes. Hong Kong Physiotherapy Journal, 40 (02): 121-132, 2020

27- ILLI S.K., HELD U., FRANK I. and SPENGLER C.M.: Effect of respiratory muscle training on exercise performance in healthy individuals. Sports Medicine, 42 (8): 707 $724,2012$.

28- SPERLICH B., FRICKE H., De MARÉES M., LINVILLE J.W. and MESTER J.: Does respiratory muscle training increase physical performance? Military Medicine, 174 (9), 977-982, 2009. 


\section{تأثير التنفس العميق على القدرة الوظيفية

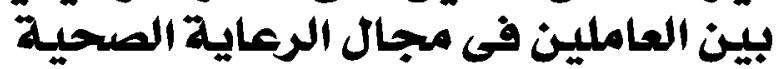

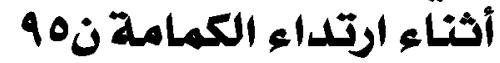

تعرض جائحة فيروس كورنا المستجد العالم للخطر بسبب انتثار قطرات التنفس المصابة بالفيرسو. يرتدى العاملون فى مجال الرعاية

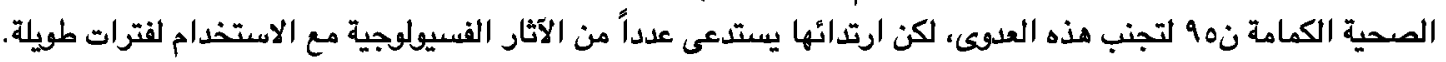

الهدف من الدراسة: قياس تأثير التفس العميق على القدرة الوظيفية بين العاملين فى مجال الرعاية الصحية أثناء ارتداء الكمامة نه9.

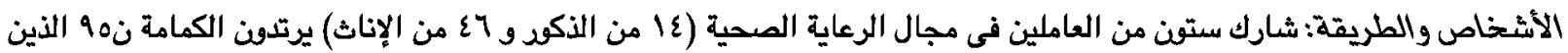

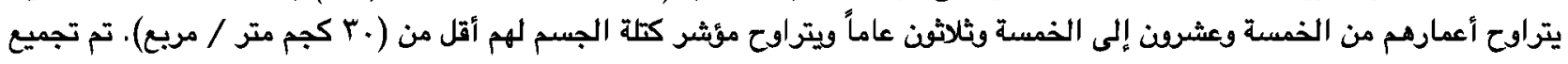

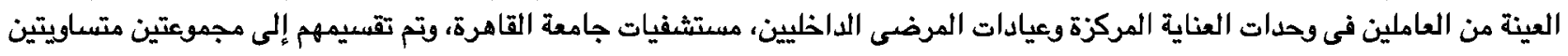

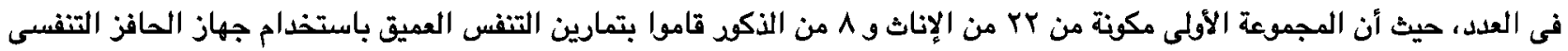

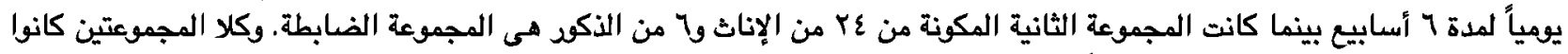

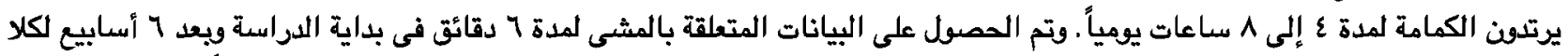

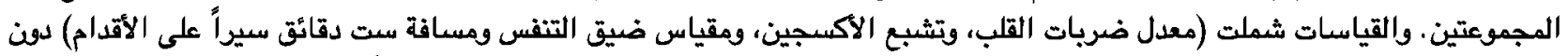

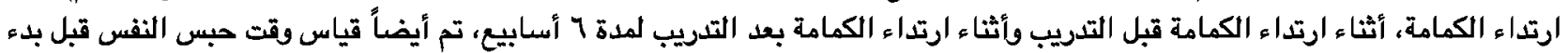

ونهاية الدراسة.

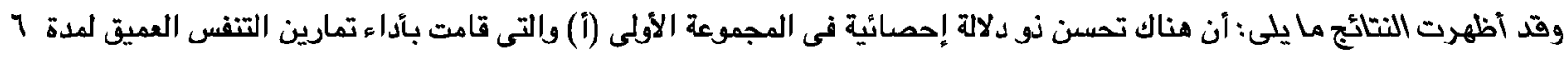

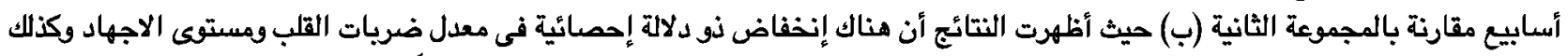

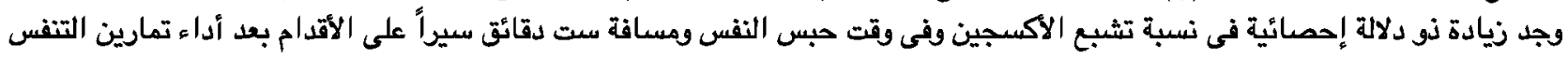

العميق فى مجموعة الدراسة (أ) مقارنة مع المجموعة الفية الضابطة (ب).

وبعد مناقشة هذه النتائج وتحليلها قد تيين أن التدريب على التنفس العميق يحسن من القدرة الوظيفية للعاملين فى مجال الرعاية الصحية أثناء ارتدائهم الكمادة نهوه 90 